\title{
A Review of a Collaborative Online International Learning
}

\author{
https://doi.org/10.3991/ijep.v10i1.11678 \\ Philip Appiah-Kubi ${ }^{(凶)}$ \\ University of Dayton, Ohio, USA \\ pappiahkubi1@udayton.edu \\ Ebenezer Annan \\ University of Ghana, Accra, Ghana
}

\begin{abstract}
Globalization has exacerbated the need for engineers who are capable of working in a cross-cultural environment. Multinational companies continuously seek for engineers who are interculturally competent and capable of conducting business successfully in a cross-cultural environment. However, the skills required to be successful in a multicultural environment are difficult to be taught in the traditional classroom. One of the most effective approaches to acquiring intercultural competency skills is through experiential learning. It is, therefore, not surprising that most colleges all over the world are devoting resources towards the internationalization of their classrooms and the campus community. This ensures that students are provided with a diverse environment, so they can learn from, and about diverse cultures to enhance their intercultural competency skills. Another effective approach is the study abroad programs, which require students to travel to different countries. However, these approaches require a lot of resources that may not be available to the less fortunate students. Therefore, a more cost-effective approach, such as Collaborative Online International Learning (COIL), is receiving a lot of attention in recent years. In this study, some engineering technology students participated in a 8-week long COIL program with materials engineering students from different languacultural and geographical regions. This study reviews the results and compares the performance of the COIL students with those who were not involved in the study. It was observed that the COIL teams performed significantly better on the project work. In addition, $70 \%$ (of the 11 students from the University of Ghana) and $85 \%$ (of the 20 students from the University of Dayton) respectively reported that the collaboration was either effective or very effective.
\end{abstract}

Keywords - Collaborative learning, intercultural competence, project management, cooperative learning, COIL

\section{$1 \quad$ Introduction}

Collaborative Online International Learning (COIL) is a pedagogy that helps to create an environment to foster the development of intercultural competence skills with 
the use of technology to connect classrooms in distinct geographical locations [1-4]. To fully benefit from COIL, the classrooms must be in geographical regions with different languacultural background [2]. COIL usually involves a structured collaboration between two or more faculty members who teach similar or related courses at the college level. These faculty members can create a shared syllabus, course material, or outcomes with a common experiential learning tool. The experiential learning tool, which can be in the form of project work, serves as the medium for student collaboration. The faculty members assume shared responsibility in mentoring the students on the collaborations. The project can run from a few weeks (4-8) to a semester-long. The main idea is to get the students to be more global thinkers as they work collaboratively on a project with students from different cultural backgrounds. Esche [1] explains that COIL provides an opportunity for economically disadvantaged students who may not be able to participate in travel abroad to also benefit from an intercultural learning environment without traveling. Even though the experience is virtual, it is widely believed that the experience it provides is highly beneficial to students' development in intercultural competence.

COIL requires investment in technology and for participants who are comfortable with online communication technologies supported by various colleges through their distance or e-learning facilities. Although distance learning is well established, COIL has unique attributes that distinguish it from synchronous and asynchronous distance learning. Esche [1] explains that distance learning could include COIL component and an experiential learning component that requires student collaborations. The inclusion of COIL component in a course benefits students and faculty members through the sharing of course material. This may be done with courses that are similar in scope or complementary and apply project-based learning. This paper discusses the experiences from a COIL project, which involved engineering technology students in a project management course from the University of Dayton (UD), and materials science and engineering students in environmental engineering course from the University of Ghana (UG). Project management is a course that can easily be used for COIL with several courses. The environmental engineering course has several areas where the use of project management knowledge becomes relevant and applicable.

The Project Management Institute (PMI) defines project management as "the application of knowledge, skills, tools, and techniques to project activities to meet the project requirements" [5]. The knowledge, tools, techniques, and skills of project management are universal and applicable to almost every project. However, cultural and other factors could impede the application of the project management knowledge areas. Different cultures have different forms of communication, which project managers or engineers need to understand in order to be successful. Project management is a universal tool to get engineers exposed to an environment that will provide the room to enhance their intercultural competence skills. As a result, the two engineering faculty members collaborated with their classes in the spring semester of 2019 on a COIL. The collaboration started with the establishment of the faculty to faculty partnership in the summer of 2018 through a global education seminar which is discussed later in the paper. The expectations were to share curricula documents and create a diverse environment where students can enhance their intercultural competency skills through COIL. 


\subsection{Intercultural competence}

Researchers define intercultural competence (ICC) in several different ways [6-10]; however, three main competence domains are shared. Alvino [11] explains that the ability to cooperate and comply with various points of view, developing relationships and maintaining them, and appropriate and effective communication with little or no distortion are the shared goals of interculturalism [1]. Other research works also articulated the attributes of effective intercultural competence. Torre [12] concluded that the most reliable measure of effective intercultural competence is the utilization of one's cultural experience to positively evaluate "differences among people" [12]. Kleinjans [13] observed that the ability to see people first, knowing that people are generally good, knowing other culture's values, and feeling comfortable in the midst of other people as some of the traits of effective intercultural competence [13]. Even though there has been a lot of research about intercultural competence in recent years, Deardorff explains that it lacks a global definition because of the complexity in building consensus on the components of intercultural competence [10].

There is a consensus on the need for colleges to ensure that their students are given the opportunities and environment to enhance their ICC. Consequently, colleges are using programs such as study abroad to get students exposed to multicultural environments. However, the assessment of ICC, as well as its components, have received varied attempts. Terenzini and Upcraft [14] observed that "while assessing the purported outcomes of our efforts with students is probably the most important assessment we do, it is seldom done, rarely done well, and when it is done, the results are seldom used effectively" [14]. Among the challenges of ICC assessment is the identification of the appropriate assessment component. Deardorff [10] explains that higher education institutions must be able to differentiate between effective and non-effective ICC assessment tools. Consequently, Deardorff designed an assessment tool for assessing "intercultural competence as a student outcome for internationalization" [10].

Deardorff's intercultural model for assessing ICC involves inputs such as institutional support or resources invested to generate activities for internationalization (such as the involvement of faculties in internationalization activities, COIL) through which outputs (such as the number of students involved in the activities) are generated. This input - process - output model, in the long term, is expected to have a positive impact on internationalization due to the churning out of students who will be interculturally competent [10]. The empirical study also concluded that direct observation by others from the host culture, judgment by others and self, student interviews, and case studies are the assessment methodologies unanimously acceptable by academic administrators involved in institutional internationalization programs. Other self-reporting instruments and focus groups are equally perceived as effective in assessing ICC [10]. 


\section{$2 \quad$ Literature Review}

\subsection{Internationalization}

Tanhueco-Nepomuceno [15] defines internationalization as "an institutional process that in some way internalizes the concept of openness to the world in all the activities and organizational aspects of the university, and it may even launch an internal transformation to prepare the university to act more directly on the international or global scene" [15] The integration of elements of internationalization into teaching, research, and service help universities to promote academic mobility [15]. Some of the ways universities internationalize are seen in attracting, retaining and supporting the academic success of international students, faculty collaborations on teaching and research, study abroad programs, and other outreach service activities. Internationalization has become a critical component of the higher education fabric in the 21 st century, and it comes with opportunities as well as constraints [16] that must be well understood. In order to harness the enormous opportunities presented by internationalization, one requires a strategic approach [16] in the planning and execution of the activities aimed at internationalization.

Knight [17] developed a seven-phased, non-linear fluid model for internationalization process in Higher Education Institutions (HEI); awareness, commitment, planning, structure, operationalization, evaluation, and recognition [15, 17]. This, according to Tanhueco [15], internationalization must become a critical component of the institutional culture. An HEI that has a strong culture for institutionalization will be better placed to implement Knight's process model of awareness that leads to a commitment of resources, planning, and structuring the internationalization activities. The process model is a two-way iterative process. Higher Education Institutions involved in internationalization provide a better opportunity for their constituents to grow in becoming global thinkers. McCarthy [18] explains that internationalization of HEI provides the opportunity for a fresh evaluation of institutional mission, through which boundaries and outreach could be extended. Ninnes and Hellsten [19] explain that internationalization help to prepare students to be more competitive in the diverse global economy. In addition, academics, in general, become change agents for societal progress [15]. It is, therefore, not surprising that internationalization in HEI is attracting a lot of investment in recent years aimed at improving intercultural competence [19].

The demand for graduates who are competent and ready to excel in the complex global economy has made internationalization a global phenomenon [20]. Thus, students who are exposed to internationalization activities are expected to acquire intercultural skills necessary to become interculturally competent. However, there is a lack of consensus about the definition of ICC and how it can be acquired. A popular definition of ICC derived from the collective decision of academic administrators and scholars is "one's ability to communicate effectively and appropriately in intercultural situations based on one's intercultural knowledge, skills, and attitudes" [10]. Due to the multidimensionality nature of ICC, various approaches have been attempted in assessing it. However, none of the qualitative and quantitative assessment strategies ho- 
listically determines the optimum attainment of ICC. Therefore, Deardorff [10] developed a multidimensional Pyramid Model of Intercultural competence which visualizes ICC as an iterative developmental process [10].

Wolff and Borzikowski [21] also define ICC "as a complex of abilities that are needed to interact with people from other cultures adequately and effectively" [21]. The demand for these complex skills will continue to grow with the increase in digital mobility. Intercultural collaborations are expected to continue increasing as people become more mobile through transcontinental and digital migration [21]. The convenience of digital migration has added to the demand for graduates who can communicate and interact effectively and adequately in virtual meetings with people from different cultures. Collaborative learning helps to create a fertile environment for ICC development.

\subsection{Collaborative learning}

Collaborative learning is defined as a broad term encompassing pedagogies that rely on "joint intellectual effort by students, or students and their teachers together" [3] [29]. Pedagogies, such as team-based service learning, also provide opportunities for nonprofit organizations to get involved in the collaboration. A nonprofit organization, unlike other organizations, usually has limited resources and usually relies on volunteers to complete some major activities. Hence, when they serve as clients for a collaborative project, they do not become spectators but collaborative partners [22]. This means that collaborative learning can be designed to include students-client collaborations. In this case, the working teams of two or more students pursue a student to student collaboration, as well as student-client collaboration which makes the client a principal entity in the collaborative process [30]. Even though there are various forms of collaborative learning, Smith and MacGregor [3] explain that it falls typically under the application of course materials or cumulative knowledge from past classes and other academic experiences to solve a problem [3]. Thus, teachers, instead of serving as knowledge transmitting vessels, act as facilitators and designers of the collaborative environment and the experience.

Collaborative learning has various attributes such as active learning and constructive process. This means that students do not only take in information passively or actively, rather, they become critical entities in their learning process and are able to "reflect on their own perceptions, assumptions, and new understandings, and those of their peers" [32]. Students iteratively apply content knowledge to solve a problem through a concerted effort that emphasizes the collective goal than individual achievement. This means that a team effort, (as opposed to just a divide and conquer approach) is an ingredient of successful collaborative learning. If well designed and implemented, collaborative learning should put a lot of emphasis on the processes through which the problem is solved. Some group works only emphasize and celebrate the attainment of a solution to a problem or product without paying attention to the processes through which the solution was obtained. That will be more of group work and not collaborative [3] [31]. Collaborative learning requires individual accountability, sharing and helping each other for the common project goal, and to enhance participant's social and intercultural competence. Students do not necessarily "divide and conquer" [3], but more 
deliberate interactions are required [3] [32], which help in the formation of a "climate of respect" [33] and a sense of appreciation among students [33].

Collaborative learning thrives when diversity of perspectives is encouraged. This means that a welcoming environment must be created for students to freely express their diverse ideas in order to achieve the desired interactions [3, 4, 23]. The subjects in a collaborative learning environment get enlightened by the diversity of perspectives [3], which positively impacts student learning [34]. An environment that supports diversity of perspectives helps students to talk, and it is the talking "through which much of the learning occurs" [24]. This led Smith and MacGregor to conclude that collaborative is: "inherently social, active and constructive, and requires diverse learners who are motivated or empowered to think critically on challenging problems [3]." Collaborative learning can be developed extemporaneously as a result of the interest shown by students in a series of sequential group works, or it can be a well-structured set of activities. It helps to expose students to pragmatic teamwork and social skills needed to succeed in their future professions [30, 34, 35]. However, collaborative learning is more beneficial to junior and senior-level students than those in the sophomore and freshman levels [36]. Instructors must always ensure that the strategies used for peer evaluations, role assignments, and peer ratings used during collaborative learning support effective collaboration [37].

Cooperative learning overlaps with collaborative learning. Cooperative learning falls at the end of the collaborative learning continuum where the learning processes, activities, and experiences are highly organized [3, 23]. With cooperative learning, the objective is for students to synergistically work together to maximize their own and each other's learning [25]. These pedagogies help students to develop their interpersonal and social skills [30]. Regular debriefing helps the team members in cooperative and collaborative learn to reflect on the learning process and to device ways to improve their effectiveness $[3,25,26]$. Thus, social, interpersonal, and academic skills are incorporated into cooperative learning and are all critical to the success of the class. To incorporate intercultural competence into cooperative learning, the environment must be created and that is one of the objectives for COIL. COIL provides the opportunity to create a diverse environment for students to enhance their social, interpersonal, and intercultural competence. However, if the collaboration involves students from similar cultural backgrounds, it limits the scope of intercultural strategic fit, which is the depth of cultural variability available for the students to explore. Providing prompt feedback to students, coaching them to develop a positive attitude towards the collaboration, and balancing instructor workload are some strategies that may help to enhance the strategic fit [38]. In addition, the technology used by instructors and students must enhance collaboration, so it does not divert the attention from the collaboration [39]. 


\section{$3 \quad$ Methodology}

\subsection{Developing the partnership for COIL}

Perhaps, the most critical and challenging piece in the COIL process is identifying and developing a partnership. The SUNY COIL Center [2] explains that faculty members who are interested in COIL can start by looking into their professional network and see if there is any faculty member in a geographical region that has an acceptable cultural diversity and teaches a class with the same or overlapping goals. Once that has been identified, the next step will be to reach out to the colleague and discuss the prospects of "COILing". Institutions with the resources and a stronger commitment to COIL are also able to facilitate programs that connect faculty members to peers in geographical regions of institutional interest. That was the case for the COIL program discussed in this paper.

The University of Dayton's Center for International Programs (CIP) has a Global Education Seminar (GES) program aimed at "motivating new scholarly projects and expand international faculty exchanges and grant opportunities" [27]. The GES program, which has been taking faculty members to several countries in Asia, South America, and Africa, has the following objectives: "accelerate the revision of existing curriculum, both at the course and the program levels, to incorporate academically meaningful global and intercultural perspectives; familiarize a growing body of UD faculty, who formerly have had little international experience, with international locations as sites for academic exploration and study; strengthen the University's current network of international resources and relationships (to) enrich and support curriculum revision, motivate new scholarly projects, and expand international faculty exchanges and grant opportunities; foster an appreciation of and engagement with current UD initiatives and partnerships at the site, as well as on-campus expertise; align more closely on-campus curricula with education abroad opportunities and support the development of signature education abroad sites" [27].

As can be inferred from the seminar objectives, the institution has committed resources into internationalization and CIP facilitates partnership development. Since seminar participants travel as a cohort, the CIP identified the higher education institutions that offered courses similar to the background of the cohort. Once those institutions were identified, the faculty members in the cohort were asked to review the background information of the partner institutions and identify potential collaborators. The CIP worked with their counterparts in the partner institutions (with faculty inputs) to plan the onsite meetings. It is worth mentioning that not all of the background information about the individual collaborators are easily accessible online which made CIP's facilitation very crucial. A lot of the onsite meetings were conducted with partner institutions as a cohort. However, faculty members had individual sessions to discuss potential collaborative opportunities with the partners. It was through the 2018 GES that the partnership for the COIL program discussed in this paper was established.

About 8 weeks before the start of the fall 2018 semester, the two faculties had a Skype meeting to discuss the course syllabi, objectives, expected workload and how 
that may be shared, when the projects will be assigned to the student teams, team formations (number of students per team), project types, the lead faculty, assessment tools, and the expectations. Another meeting was held approximately two weeks before the semester started to finalize the syllabi. Since the classes were different (project management and environmental engineering), the faculty members maintained the sovereignty of the respective course objectives but devoted a significant percentage of a course grade to the class projects. Common project deliverables and milestones were assigned to the collaborating teams from both institutions. The project-based component of the two classes made it possible for the COIL. Figure 1 provides details about the methodology used.

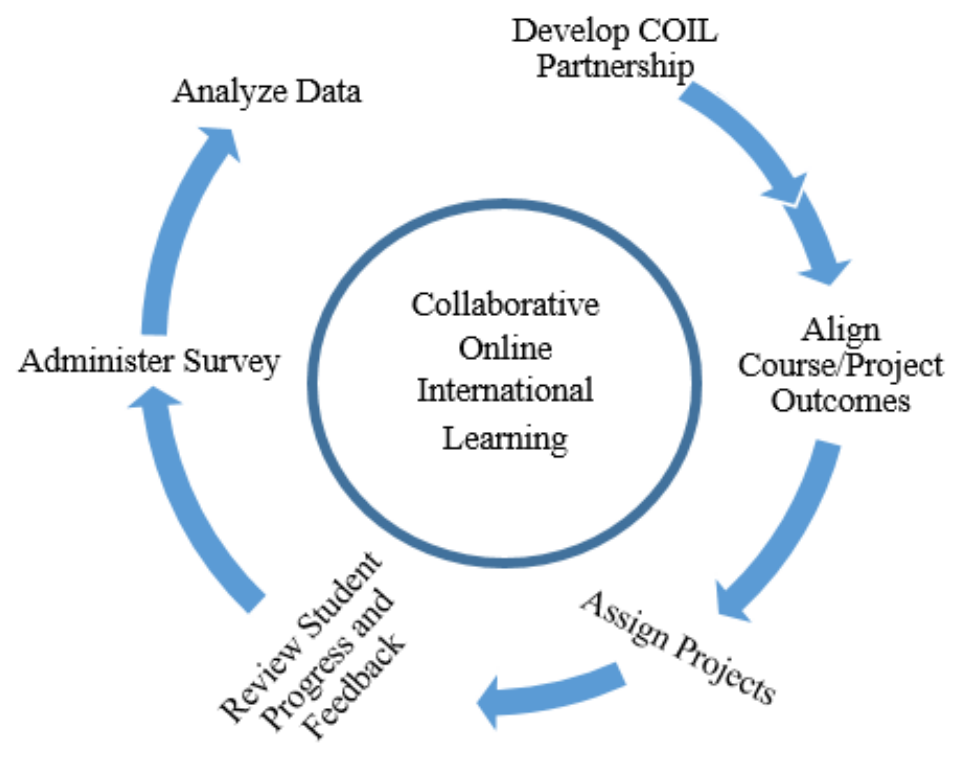

Fig. 1. The COIL Research Model

\subsection{Delivering the COIL}

The students were briefed on the first day of class about the COIL component of the classes. Attention was deliberately devoted to the following:

- The reason for COIL in the courses

- The expectation from the COIL

- Types of projects

- Possible challenges/risks

- Opportunities

- Logistics (laptops, internet access, etc.) 
The courses were delivered in the traditional lecture format asynchronously by the respective instructors. By week six, the students have had enough preparation and technical knowledge to start working on the projects. At that point, the teams were formed and assigned to the projects. Four teams from UD collaborated with the UG teams and instructors. Each team worked on a different project with an external client. One of the projects was the remodeling of the Dayton International Peace Museum to make it stand out for easy identification. It was also meant to enhance visitors' experience at the only international peace museum in the United States of America.

After the projects were assigned, the students worked with their teams outside class time through weekly virtual (Skype) meetings, WhatsApp, and emails. Prior to their first meetings, the students and faculty members recorded and shared a short self-introduction video ( $1-2$ minutes). The videos served as an ice-breaking exercise for the students to get to know each collaborating partner. As a privacy condition, the students were instructed that another person's video cannot be shared or posted on a social media platform or on the internet without written consent. The collaborating teams were all required to submit proof of their virtual video meetings with the list of attendees and meeting minutes. They also presented biweekly oral updates of their progress to the lead instructor and external client. The students were encouraged to resolve all conflicts, document challenges, and copy the instructors in all email exchanges. Two weeks to the end of the semester, the teams submitted a final report and conducted oral presentations, which concluded the COIL. The results of a post-project Google survey completed by both classes as well as the exams and project performance of the UD students are presented in the next section.

\section{$4 \quad$ Results and Discussions}

All of the 11 students (who were seniors) from the University of Ghana completed the survey. Approximately $38 \%$ and $27 \%$ reported that they have been involved in a form of collaborative learning course 4 - 5 times, and $2-3$ times respectively. However, this was the first time the entire class did COIL. Eighteen percent (also reported that they have been more than 7 times involved in courses requiring collaboration or team experience. Team experience was defined as any situation that required a student to work with one or more students on a project or assignment for at least three weeks with individual and group accountability. All of the students reported that their collaborative learning experience with the students from the University of Dayton was positive. It was revealing to learn that approximately $27 \%$ of the students stated that they found it difficult to communicate their thoughts or opinions to the collaborative group. Two students who provided further details for this situation explained that they were sometimes uneasy and preferred to speak through their team leader. However, the majority $(55 \%)$ of the students stated that it was easy for them to communicate.

Forty percent $(40 \%)$ of the students also reported that it was easy to agree on a time to meet with their collaborators. The other $60 \%$ found it difficult or very difficult finding time to meet. This confirms some of the frustrations during the early stages of the collaboration where some teams reported about their struggle in finding time to meet. 
Even though it was difficult finding time to meet, $70 \%$ of the student reported that their collaborative partners are either effective or very effective. Among the things that the students liked most about working on the team projects were "the fact that everyone shares ideas to make the project a better one", "we share ideas towards a common goal", "it makes the work easier to finish", and "new friends are made and also get to learn from under people."

The University of Dayton Students were also exposed to COIL for the first time, and 20 (out of 26) students responded to the survey. The students were either juniors or seniors, and $65 \%$ of the respondents participated in the COIL program. Forty-five percent $(45 \%)$ and $25 \%$ respectively reported that they have been involved in a collaborative learning or team experience course more than 7 times and $4-5$ times. In addition, $15 \%$ each responded that they have had collaborative experience $6-7$ times and $2-3$ times. The COIL students reported positive experience $(65 \%)$, and very positive $(30 \%)$ experience from their collaboration with the students from the University of Ghana. While $27 \%$ of the students from the UG reported that it was difficult to communicate their thoughts, $65 \%$ and $25 \%$ of the UD students felt that it was easy or very easy respectively to communicate their thoughts across the teams. Similar to the experience from the UG students, $45 \%$ of UD students reported that it was either difficult or very difficult to find time to meet. The remaining felt it was very easy $(15 \%)$ or easy $(40 \%)$ to find time to meet. In addition, the UD students felt that their collaborators were effective $(65 \%)$, very effective $(20 \%)$, and not too effective $(15 \%)$.

As part of the project work, the students from the University of Dayton completed two exams. The first exam was given three weeks after the project was assigned and the second exam was given at the completion of the project. Each exam covered different course materials with no overlap. Mixed ANOVA (in SPSS) was conducted to test whether the COIL teams and the students who were not involved with COIL (No COIL) had statistically significant differences in their scores for exam 1, exam 2, the project work, and the total class scores. Initial data exploration revealed that all of the variables were normally distributed $(\mathrm{p}>0.05)$. In addition, Levene's test for equality of variance was insignificant $(p>0.05)$ for the variables except Exam $2(p=0.015)$ and Total Score $(p=0.034)$. Therefore, exam 2 and the total exam scores were excluded from the Mixed ANOVA test. Table 1 shows the mean and standard deviations for the variables.

Table 1. The mean and standard deviation of variables

\begin{tabular}{|l|l|c|c|}
\hline & & Mean & Std. Deviation \\
\hline \multirow{2}{*}{ Exam 1 } & No COIL & 59.2308 & 13.89786 \\
\cline { 2 - 4 } & COIL & 66.2308 & 8.15633 \\
\hline \multirow{2}{*}{ Exam 2 } & No COIL & 57.9231 & 22.81159 \\
\cline { 2 - 4 } & COIL & 64.1154 & 13.30438 \\
\hline \multirow{2}{*}{ Project Work } & No COIL & 82.0723 & 2.69308 \\
\cline { 2 - 4 } & COIL & 89.8392 & 4.25803 \\
\hline \multirow{2}{*}{ Total Score } & No COIL & 199.2262 & 36.5716 \\
\cline { 2 - 4 } & COIL & 220.1854 & 18.28446 \\
\hline
\end{tabular}


It can be seen that teams that participated in the COIL program collectively performed better in exam 1, exam 2, and the project work. The mean from the COIL teams was higher than the No COIL teams on all the performance measures. There were also a lot of dispersions in the scores of the No COIL teams as can be seen from the relatively higher standard deviation in Table 1. It can also be observed that the students' score on the second exam, which was graded out of 100 points were significantly lower than the mean of their exam 1 score which was graded out of 80 points.

With the remaining two variables (Exam 1 and Project score), a Mixed ANOVA test was conducted. This means that the Sphericity assumption is not an issue since three variables are needed for Sphericity be of a concern [28]. The results indicated that there is a statistically significant difference $(\mathrm{p}<0.05)$ between the scores of the two groups (COIL vs. No COIL). The same conclusion can be drawn from the Multivariate (which does not require Sphericity [28]) test output (table 2) as the Pillai's trace and all of the remaining statistics indicate a statistical significance $(\mathrm{p}<0.05)$, and large effect size.

Table 2. Multivariate test output

\begin{tabular}{|l|c|c|c|c|}
\hline \multicolumn{1}{|c|}{ Statistic } & Value & F & Sig. & Effect size \\
\hline Pillai's trace & .828 & 115.549 & .000 & .828 \\
\hline Wilks' lambda & .172 & 115.549 & .000 & .828 \\
\hline Hotelling's trace & 4.815 & 115.549 & .000 & .828 \\
\hline Roy's largest root & 4.815 & 115.549 & .000 & .828 \\
\hline
\end{tabular}

Pairwise comparison indicated that the COIL group performed better than the No COIL group. Specifically, in the first exam, the COIL group performed significantly better $(\mathrm{p}<0.05)$ than the No COIL group. The same can be said about the project score which was the main tool for the collaboration. The differences were not only statistically significant but practical as well. For example, the mean of exam 1 for the COIL group (in percentage) is equivalent to letter grade B (83\%), as opposed to $74 \%$ for the No COIL group which is also equivalent to letter grade $\mathrm{C}$ based on the grading scale at UD. Similarly, the project score, graded out of 100 points, represents a mean letter grade of $\mathrm{B}+$ for the COIL group, and $\mathrm{B}$ - for No COIL group.

The COIL team also did practically better on the second exam than the No COIL team. However, both teams' performance was lower in the second exam compared to the first exam. This may be attributed to the fact that the second exam was given during the finals weeks when the project report was also due. With a lot of due dates from other classes, students may be stressed out, hence, their performance may be less than optimum.

\section{Conclusion}

This paper presents the results of a limited study where project management was used as a tool for collaboration for engineering students. Project management presents universal tools that are applicable to almost every academic field, hence, making it eas- 
ier to find collaborators from different disciplines. For this research, engineering technology students from the University of Dayton (UD) collaborated with environmental engineering students from the University of Ghana (UG) on an 8-week long project. In addition to the project, the UD students took two exams and the results were compared. Moreover, a post-project completion survey was completed by the students from the two colleges.

The survey results indicated that the students generally perceived collaboration as a positive experience, which is consistent with the literature [40]. The students who participated in the COIL had a higher mean score on the exams (1 and 2). The differences in the scores were practically significant as they represented different letter grades. The project work, which was the main tool for the collaboration, also resulted in statistically significant different scores, with the COIL team performing significantly better than the No COIL team. The open-ended questions did not generate a lot of varied responses from the $72 \%$ (8) UG students and $30 \%$ (6) UD students who responded. It can be inferred from approximately $79 \%$ of the responses that the COIL component the students liked most was "the fact that everyone shares ideas to make the project a better one." In addition, 50\% reported that they liked sharing ideas towards a common goal from different perspectives. Moreover, approximately $36 \%$ reported that COIL makes the project work easier to finish, and $21 \%$ liked making new friends and "learning from under people".

From this limited study, it may be inferred that the COIL can improve student performance on project work. The collaboration creates an environment for diverse idea generation. Thus, the cultural diversity through the COIL program helps students to approach a project from different perspectives which may end up with a better response or solution approach to the objectives of the project. Even though this is desirable, it also comes with challenges as the students must be able to break through the cultural barrier, work around the different time zones, and also, communicate effectively among the teams. This is the reason why COIL requires more faculty time. However, it provides the opportunity for a more student-faculty interaction, which could be the main reason why the COIL teams performed relatively better on the project that the No COIL team. For this study, the challenges of the collaboration forced students to utilize faculty office hours regularly to discuss the project, preliminary findings, and the challenges from the collaboration. Through those meetings, discussions went into areas that would have otherwise remained unchartered. Hence, providing further clarification on the project. What this means is that instructors of COIL programs must devote additional time to prepare the teams, and coordinate activities with the other faculty, otherwise, the challenges will limit the opportunities that COIL promises.

\section{$6 \quad$ Limitations of the Study}

COIL is an innovative way to improve cultural diversity in the classroom, and it has enormous prospects for internationalization. However, there are numerous challenges that must be addressed in order to harvest the opportunities it presents. This study is a demonstration of how COIL can be introduced into classes that have project-based 
learning components, and the impact it can have on student performance. However, the limited number of students, and the fact that the study involved two classes in a semester makes it difficult to generalize the results of the study. Therefore, further studies are required to validate the observations and conclusions reached by this study.

\section{$7 \quad$ Acknowledgement}

The authors would like to thank Professor Scott Segalewitz, Associate Dean for Experiential Learning and Student Success, University of Dayton for his support for the COIL program. In addition, we like to thank Professor Boateng Onwona-Agyemen, Dean of Engineering Sciences, University of Ghana for his support throughout the process. We also like to thank Robin Olesinski, the students who participated in this COIL study from both Universities, and the Center for International Programs, University of Dayton for their support.

\section{References}

[1] M. Esche, "Incorporating Collaborative Online International Learning (COIL) into Study Abroad Courses: A Training Design," ed: Capstone Collection. 3096. https://digitalcollections.sit.edu/capstones/3096, 2018.

[2] Suny COIL Center, "Faculty Guide for Collaborative Online International Learning Course Development," vol. 1.4, ed: The Center for Collaborative Online International Learning. The State University of New York Global Center, 116 E. 55th St. New York, NY 10022.

[3] B. L. Smith and J. T. MacGregor, "What is collaborative learning? In A. Goodsell, M. Maher, V. Tinto, B. L. Smith, \& J. T. MacGregor (Eds.), Collaborative learning: A sourcebook for higher education.," ed: University Park, PA: Pennsylvania State University, National Center on Postsecondary Teaching, Learning, and Assessment, 1992.

[4] J. A. Hughes Caplow and C. M. Kardash, "Collaborative learning activities in graduate courses," Innovative Higher Education, vol. 19, no. 3, pp. 207-221, 1995/03/01 1995,. https://doi.org/10.1007/bf01191220

[5] Project Management Institute, "What is Project Management?," 2019. [Online]. Available at https://www.pmi.org/about/learn-about-pmi/what-is-project-management. [Accessed: 8 Aug - 2019]

[6] B. D. Ruben, "Assessing Communication Competency for Intercultural Adaptation," Group \& Organization Studies, vol. 1, no. 3, pp. 334-354, 1976/09/01 1976, https://doi. org/10.1177/105960117600100308.

[7] J. Koester and M. Olebe, "The behavioral assessment scale for intercultural communication effectiveness," International Journal of Intercultural Relations, vol. 12, no. 3, pp. 233-246, 1988, https://doi.org/10.1016/0147-1767(88)90017-x.

[8] Y. Kim, "Intercultural communication competence: A systems-thinking view. In W. B. Gudykunst \& Y. Y. Kim (Eds.), Readings on communicating with strangers: An approach to intercultural communication (pp. 371-381).", ed. New York: McGraw-Hill, 1992.

[9] V. Terpstra, "Review of Hampden-Turner and Trompenaars: Building Cross- Cultural Competence: How to Create Wealth from Conflicting Values," International Marketing Review, vol. 19, no. 2, pp. 204-206, 2002/04/01 2002, https://doi.org/10.1108/imr.2002. 19.2.204.1. 
[10] D. K. Deardorff, "Identification and Assessment of Intercultural Competence as a Student Outcome of Internationalization," Journal of Studies in International Education, vol. 10, no. 3, pp. 241-266, 2006/09/01 2006, https://doi.org/10.1177/1028315306287002.

[11] E. F. Alvino, "A CENTRAL CONCERN: DEVELOPING INTERCULTURAL COMPETENCE.," ed: School for International Training (SIT) Occasional Papers Series, Addressing Intercultural Education, Training \& Service., 2000.

[12] M. Torre, "The selection of personnel for international service," The International Executive, vol. 6, no. 2, pp. 5-6, 1964/03/01 1964, doi: 10.1002/tie.5060060202.

[13] E. Kleinjans, "Opening remarks at a conference on world communication held at the East West Center, Honolulu, HI.", ed, 1972.

[14] P. T. Terenzini and M. L. Upcraft, "Assessing programs and service outcomes. In M. L. Upcraft \& J. H. Schuh (Eds.), Assessment in student affairs: A guide for practitioners (pp. 217-239). San Francisco: Jossey-Bass.," ed, 1996. https://doi.org/10.7203/relieve.9.1.4352

[15] L. Tanhueco-Nepomuceno, "Internationalization among selected HEIs in the ASEAN region: Basis for a proposed framework for an internationalized campus," International Journal of Educational Development, vol. 65, pp. 152-171, 2019/03/01/ 2019, https://doi.org/ 10.1016/j.ijedudev.2018.07.003.

[16] K. Jane, "Internationalization: A Decade of Changes and Challenges," International Higher Education, vol. 0, no. 50, 03/25 2015, https://doi.org/10.6017/ihe.2008.50.8001.

[17] J. Knight, Internationalization at Canadian Universities [microform] : The Changing Landscape $=$ L'internationalization dans les universites Canadiennes: le nouveau paysage / Jane Knight (no. Accessed from https://nla.gov.au/nla.cat-vn5607886). [S.1.]: Distributed by ERIC Clearinghouse, 1995.

[18] M. S. Joann, "A Roadmap for Creating the Global Campus," ed: Chronicle of Higher Education, 2007.

[19] P. Ninnes and M. Hellstén, Internationalizing Higher Education: Critical explorations of pedagogy and policy. 2005.

[20] L. Rumbley, P. Altbach, and 1. reisberg, "Internationalization within the higher education context," 2012, pp. 3-26. https://doi.org/10.4135/9781452218397.n1

[21] F. Wolff and C. Borzikowsky, "Intercultural Competence by International Experiences? An Investigation of the Impact of Educational Stays Abroad on Intercultural Competence and Its Facets," Journal of Cross-Cultural Psychology, vol. 49, no. 3, pp. 488-514, 2018/04/01 2018, https://doi.org/10.1177/0022022118754721.

[22] L. P. Amy and L.-W. Elzbieta, "Group Projects Using Clients Versus Not Using Clients: Do Students Perceive Any Differences?," Journal of Marketing Education, vol. 31, no. 2, pp. 154-159, 2009/08/01 2009, https://doi.org/10.1177/0273475309334169.

[23] K. A. Smith, "Cooperative learning: Making "groupwork" work," New Directions for Teaching and Learning, vol. 1996, no. 67, pp. 71-82, 1996, https://doi.org/10.1002/tl. $\underline{37219966709 .}$.

[24] J. Golub, E. National Council of Teachers of, and P. Committee on Classroom, Focus on collaborative learning. Urbana, Ill.: National Council of Teachers of English (in English), 1988.

[25] D. W. Johnson, R.Johnson, and E.Holubec., "Circles of Learning: Coopera-tion in the Classroom," ed: Edina, MN: Interaction Book Company, 1990.

[26] D. W. Johnson and R. T. Johnson, "Learning Together and Alone: Overview and Metaanalysis," Asia Pacific Journal of Education, vol. 22, no. 1, pp. 95-105, 2002/01/01 2002, https://doi.org/10.1080/0218879020220110. 
[27] Center for International Programs (CIP) - University of Dayton, "Global Education Seminar,". 2019. [Online]. Available at: https://udayton.edu/international/connect/faculty_staff/ges.php. [Accessed: 25 - July - 2019]

[28] A. Field, Discovering Statistics Using IBM Statistics (fourth ed.). London, (England): Sage Publications Ltd, 2013.

[29] M. Laal and S. M. Ghodsi, "Benefits of collaborative learning," Procedia - Social and Behavioral Sciences, vol. 31, pp. 486-490, 2012/01/01/ 2012, https://doi.org/10.1016/j.sbspro. 2011.12.091.

[30] K. Scager, J. Boonstra, T. Peeters, J. Vulperhorst, and F. Wiegant, "Collaborative Learning in Higher Education: Evoking Positive Interdependence," (in eng), CBE life sciences education, vol. 15, no. 4, p. ar69, Winter 2016, https://doi.org/10.1187/cbe.16-07-0219

[31] Brame, C.J. and Biel, R. (2015). Setting up and facilitating group work:

[32] Using cooperative learning groups effectively. Retrieved [todaysdate] from http://cft.vanderbilt.edu/guides-sub-pages/setting-up-and-facilitating-group-work-using-cooperativelearning-groups-effectively/

[33] Love, A. G., Dietrich, A., Fitzgerald, J., \& Gordon, D. (2014). Integrating collaborative learning inside and outside the classroom. Journal on Excellence in College Teaching, 25(3\&4), 177-196

[34] A. G. Love, A. Dietrich, J. Fitzgerald, and D. Gordon, "Integrating Collaborative Learning Inside and Outside of the Classroom," Journal on Excellence in College Teaching, Article vol. 25, no. 3/4, pp. 177-196, 2014.

[35] J. Zhang and Q. Cui, "Collaborative Learning in Higher Nursing Education: A Systematic Review," Journal of Professional Nursing, vol. 34, no. 5, pp. 378-388, 2018/09/01/ 2018, https://doi.org/10.1016/j.profnurs.2018.07.007.

[36] L. M. Young, C. K. Machado, and S. B. Clark, "Repurposing With Purpose: Creating a Collaborative Learning Space to Support Institutional Interprofessional Initiatives," Medical Reference Services Quarterly, vol. 34, no. 4, pp. 441-450, 2015/10/02 2015, https:// doi.org/10.1080/02763869.2015.1082377.

[37] S. A. Kalaian and R. M. Kasim, "Effectiveness of various innovative learning methods in health science classrooms: a meta-analysis," Advances in Health Sciences Education, vol. 22, no. 5, pp. 1151-1167, 2017/12/01 2017 https://doi.org/10.1007/s10459-017-9753-6

[38] Y. Chang and P. Brickman, "When Group Work Doesn't Work: Insights from Students," CBE-Life Sciences Education, vol. 17, no. 3, p. ar52, 2018/09/01 2018, https://doi.org/ 10.1187/cbe.17-09-0199.

[39] M. Pinho Lopes and J. Macedo, "Project-based learning to promote high order thinking and problem solving skills in geotechnical courses," International Journal of Engineering Pedagogy, vol. 4, 01/01 2014. https://doi.org/10.3991/ijep.v4i5.3535

[40] M. Moundridou, E. Zalavra, K. Papanikolaou, and A. Tripiniotis, "Collaboratively Developing Open Educational Resources for Engineering Educators in SlideWiki," International Journal of Engineering Pedagogy (iJEP), vol. 9, p. 95, 04/15 2019. https://doi.org/10.3991/ijep.v9i2.9959

[41] A. Lehtovuori, M. Honkala, H. Kettunen, and J. Leppävirta, "Promoting Active Learning in Electrical Engineering Basic Studies," International Journal of Engineering Pedagogy (iJEP), vol. 3, p. 5, 05/21 2013, https://doi.org/10.3991/ijep.v3is3.2653. 


\section{Authors}

Dr. Appiah-Kubi is an Assistant Professor at the University of Dayton's Engineering Management, Systems and Technology Department. He has a Ph.D. in Industrial and Systems Engineering and a master's degree in Aviation Systems and Flight Testing from Ohio University and The University of Tennessee, respectively. He also has a graduate certificate in Engineering Management. His research interests lie in the applications of data analytics, supply chain management, and engineering pedagogy.

Dr. Annan is a Senior Lecturer at the Department of Materials Science and Engineering, University of Ghana - Legon, Ghana. He has been teaching at the above-mentioned University for the past decade and teaches courses such as Project Management, Environmental Engineering and Solid Waste Management, Materials Processing, Electro-ceramics, etc. He has a Ph.D. in Materials Engineering from African University of Science and Technology (AUST), a World Bank sponsored graduate school and part of the Nelson Mandela Institutions across Africa. Dr. Annan holds two master's degrees from University of Hull, United Kingdom (UK) and University of Sunderland, UK in Applied Physics and Project Management respectively.

Article submitted 2019-09-14. Resubmitted 2019-11-14. Final acceptance 2019-11-16. Final version published as submitted by the authors. 